\title{
Test of Fiscal Sustainability and Causality Hypotheses for Switzerland
}

Silika PrOHL ${ }^{\mathrm{a}}$

JEL Classification: C22; C23; H60.

Keywords: Budget Deficit; Cointegration.

\section{Introduction}

The increase in government budget deficits in several developed countries has raised the issue of the long-term solvency of government finances. The most widely accepted means for governments to reduce such budgetary deficits are to cut public expenditure and adjust revenue, raise tax rates, or employ both these policy instruments simultaneously. Therefore, theoretical studies have developed several approaches to examine the favorable effects of each instrument on a governments fiscal stance, including the causality hypothesis, which specifies whether governments reduce the budgetary deficit using both policy instruments simultaneously (see PAYNE, 2003, for a review of recent empirical studies in this area).

One research stream, the public finance literature, is dominated by the view that only the use of both policy instruments can improve the governments budgetary imbalance. This approach which assumes that in a representative democratic system, budgetary decisions on taxation and allocation must be made simultaneously by the executive and legislative branches of government suggests that fiscal synchronization is an essential condition for fiscal policy solvency. In contrast, scholars that focus on the institutional separation condition (BAGHESTANI and MCNOWN, 1994) emphasize that a government taxation and allocation decisions should be made independently of each other. Alternatively, FRIEDMAN (1978) proposes a tax-spend condition in which an increase in tax rates leads to an expansion of government expenditure and consequently worsens the governments budgetary balance, implying that lowering taxes is a necessary condition

a Silika Prohl is with the Swiss Banking Institute, Plattenstr. 14, CH-8032 Zurich, Switzerland. 
for eliminating the budget deficit. However, a competitive view from the fiscal illusion literature, while agreeing that taxes influence expenditure, suggests that they have a negative effect (BUCHANAN and WaGner, 1977). Lastly, intertemporal tax smoothing theory (BARRO, 1979) implies reverse causality by suggesting that expenditure causes revenue, an approach that points to an expenditure-tax condition in which a temporary increase in government expenditure, as occurs during wars or civil disasters, causes a permanent shift in tax rates.

This present analysis uses historical Swiss federal government data to assess the direction of the causality relation between government revenue and expenditure in response to increased budget deficits. The methodology employed in this study differs from that in previous work in several respects. First, the data used to specify the causality relation between government revenue and expenditure span an unusually long period, which raises the important question of whether this causal relationship is structurally stable over the entire time period or exhibits significant structural shifts. The study thus contributes to the literature by conjecturing that the policy regime changes inevitable in macroeconomic data for such a long time-period may result in structural shifts in revenue, expenditure, and the long-run relation between them. However, if such regime changes are taken into account, a standard cointegration test would no longer be valid since it requires that the linear combination between revenue and expenditure be time invariant under the null hypothesis. Therefore, the recently employed (and more advanced) time series cointegration method, which, by incorporating structural breaks in the levels of the cointegration relationship, ensures simultaneous inferences about the presence of cointegration and the value of the cointegration vector. The results indicate that Swiss federal fiscal policy exhibited strong structural instability during the world wars supporting earlier findings (PROHL, 2007).

Second, instead of examining the causality hypothesis within a bivariate vectorautoregressive (VAR) model (as did most previous studies), this analysis estimates a vector error-correction model (VECM) because the revenue, expenditure and GNP are cointegrated. This method allows specification of both the short- and long-run causal relationships between revenue, expenditure and their response to the equilibrium term. Defining the causal relationship within this trivariate system enables assessment of the causality between revenue and expenditure.

The paper is organized as follows. Section 2 reviews the empirical literature. Section 3 gives a brief overview of the data, presents the results of the unit root and cointegration tests, and then outlines the estimated VECM. It also outlines the structural stability tests used to estimate the structural breaks in the model. Section 5 studies determinants of the budget deficit. Section 6 concludes the paper. 


\section{Related Research}

Most of the studies that empirically investigate the causal relation between revenue and expenditure employ the Granger causality test, in which the fiscal synchronization condition requires bidirectional causality between revenue and expenditure. In contrast, FrIEDMAN's (1978) tax-spend condition implies unidirectional positive causality running from revenue to expenditure, the BUCHANAN and WAGNER (1977) relation suggests that revenue negatively causes expenditure, and the expenditure-tax condition requires that expenditure positively cause revenue.

The literature that empirically investigate the causality between revenue and expenditure can be classified into two branches. The first uses econometric methodology to test the causality hypothesis by applying conventional bivariate vector autoregressive (VAR) framework. Studies that use this approach to test U.S. federal government data mostly report univariate causality between revenue and expenditure. In contrast, the second branch employs the more flexible error-correction framework, which is an appropriate method when revenue and expenditure are cointegrated. These studies usually report a bidirectional feedback relationship between revenue and expenditure.

The conventional empirical strategy used in such research is a bivariate vector autoregressive (VAR) framework that allows study of the short-run causality relation between revenue and expenditure. Using this econometric specification, MANAGE and MARLOW (1986), and RAm (1988a) report unidirectional causality running from expenditure to revenue for U.S. federal government data from 1929 to $1982 .{ }^{1}$ However, if the revenue and expenditure are cointegrated, recent studies propose a more flexible econometric strategy using an error-correction framework in which, research suggests, revenue shares a common stochastic trend with expenditure (i.e., they are cointegrated). In this case, an appropriate econometric framework for testing the causality hypothesis would be to estimate the VECM that incorporates both the short- and long-run causal relationship.

Using this vector error-correction (VECM) approach, Miller and RusseK (1989) find a feedback relation between annual revenue and expenditure for U.S. federal government data over the 1946 to 1987 period and conclude that U.S. fiscal authorities make no spending decisions in isolation from tax decisions, ${ }^{2}$ a

1 Applying the same VAR methodology, Ahiakpor and Amirkhalkhali (1989) report unidirectional causality running from revenue to expenditure for Canadian government data from 1926 to 1985.

2 However, when applying this methodology to quarterly data, Baghestani and McNown (1994) find no evidence for any causal relation between quarterly revenue and expenditure 
finding confirmed by Hasan and Sukar (1995). However, Hoover and ShefFRIN (1992) also identify structural instability in the long-run relation between revenue and expenditure caused by changes in government taxation and allocation policy rules over the 1950 to 1989 period. Indeed, when they split the sample into two subsamples around the structural break, revenue Granger-causes expenditure in the pre-break period but no causal relation emerges in the post-break period.

Overall, earlier empirical studies in this area fail to provide clear evidence of bidirectional causality between revenue and expenditure. Therefore, more recent literature suggests that assuming a bivariate relation between revenue and expenditure is too restrictive because it neglects the responses of fiscal policy to the impulses of macroeconomic policy. Rather, using a Granger causality test on a model that incorporates the effect of the GNP, Anderson, Wallace and WARNER (1986) report a robust feedback relation between revenue and expenditure for U.S. federal government data over the post-World War II period. Likewise, BoHn (1991) who employs a VECM for revenue, expenditure, and public debt expressed in GNP ratios shows that the U.S. federal government used both revenue and expenditure equally efficiently to reduce the federal budget imbalance.

Overall, the empirical research concludes that if revenue and expenditure are cointegrated, it is essential that causality analysis employ a multivariate VECM framework. Accordingly, to examine the causality hypothesis for Swiss federal historical data, we apply an error-correction framework that allows examination of both the short-run causality represented by lagged terms and the long-run causality defined by the error-correction term in the VECM. Nevertheless, we not only place more emphasis on the error-correction term as a source of the causal relation between revenue and expenditure but include the GNP in our model specification to counteract the ambiguous findings produced by many bivariate analyses as a result of the omitted variable problem. Additionally, our model also allows revenue and expenditure to respond to the policy regime changes that cause structural breaks in revenue, expenditure and the long-run relation between them. Thus, our more advanced econometric methods accommodate structural breaks in the level of the cointegration relation.

for U.S. federal government data from 1955 to 1989. Rather, they show that budgetary imbalance (defined, for example, by the error-correction term) is insignificant in the VEC-regression although evidence does exist for short-run causality running from revenue to expenditure. 


\section{The Theoretical Framework}

In this section, we derive the governments intertemporal budget constraint and specify the essential relation for the causality hypothesis.

\subsection{The Intertemporal Budget Constraint of Government}

We start with the budget constraint of the government, which in reduced form in nominal terms is given by

$$
B_{t}=G_{t}+\left(1+i_{t}\right) B_{t-1}-R_{t} .
$$

Here, $B_{t}$ represents the current stock of public debt, while $i_{t}$ denotes the ex-post nominal interest rate payable on the public debt at time $t$; correspondingly, $R_{t}$ represents the government revenue (including seigniorage), and $G_{t}$ denotes the expenditure excluding interest payments (plus transfer payments) at time $t$. To simplify the model, we do not consider the seigniorage explicitly. This equation states that the government debt should be paid off or refinanced by issuing a new debt.

It is natural to express the government budget constraint in the real terms when normalizing each variable in the condition (1) by inflation rate. Let us derive the path of public debt in real terms from (1) by

$$
b_{t}=\left(1+\rho_{t}\right) b_{t-1}-s_{t},
$$

where we have used lower-case letters to denote the corresponding upper-case variables expressed in real terms when deflating by the inflation rate, and where $\rho_{t}=\left(i_{t}-\pi_{t}\right) /\left(1+\pi_{t}\right)$ is the interest rate $i_{t}$ adjusted for inflation rate $\pi_{t}$, and $s_{t}$ denotes the real primary budget surplus (defined as a difference between the revenue and expenditure) at time $t$.

The equation (2) is a non-linear difference equation in $b_{t}$. It is stable if $\rho_{t}<0$ for all $t$, and can be solved backwards. It suggests that the real debt $(b)$ will be finite as $t \rightarrow \infty$ for any sequence of the finite primary surplus $s_{t}$ expressed as difference between the revenue and expenditure. In this case, the debt $b_{t}$ will stabilize. This recursive relation implies the explicit condition given by

$$
b_{t}=\prod_{j=1}^{t}\left(1+\rho_{j}\right) b_{0}-\left(s_{t}+\sum_{j=1}^{t-1} \prod_{i=k+1}^{t}\left(1+\rho_{i}\right) s_{j}\right)
$$


The identity yields that the asymptotic stability of $b_{t}$ can be ensured for $t \rightarrow \infty$. Given the strictly positive initial debt $b_{0}$, this relation makes any stable path of the primary deficit consistent with a stable debt.

This case is opposed to the blow-up of the debt for $t \rightarrow \infty$ for all $t$ if $\rho_{t}>0$ in relation (2). Then, the debt will explode for the increasing primary deficit in the limit. It means that the public debt will be unsustainable. The debt will be infinite regardless of the sequence of the primary deficit. This problem can be solved if the debt will be offset by matching the increasing discounted primary surplus in the future. Then, the difference-equation (2) must be solved forwards in order to obtain the intertemporal budget constraint.

Suppose that the equation (2) holds for each period to perform the recursive substitution. The intertemporal budget constraint of government is given by

$$
b_{t}=\sum_{j=0}^{\infty} E_{t}\left(\prod_{i=1}^{j} \frac{1}{\left(1+\rho_{t+i}\right)} s_{t+j}\right)+E_{t}\left(\prod_{i=1}^{j} \frac{1}{\left(1+\rho_{t+i}\right)} b_{t+j}\right),
$$

where $E_{t}[$.$] denotes the mathematical expectation conditional on information$ at time $t$.

If we assume a constant discount factor $\rho_{t}=\rho$, we can rewrite the condition (4) as

$$
b_{t}=\sum_{j=0}^{\infty} E_{t}\left(\frac{1}{1+\rho}\right)^{j+1} s_{t+j}+E_{t}\left(\frac{1}{1+\rho}\right)^{j+1} b_{t+j} .
$$

The first term on the right hand side of relation (5) describes the main objectives of the monetary and fiscal policy of the government. The trajectory of the second term in equation (5) as $t$ gets large is essential to study the sustainability of the fiscal policy.

Suggest that $E_{t}[$.$] describes the expectations of the government potential lend-$ ers at time $t$. Then, the necessary and sufficient condition for sustainability is that if $t$ gets large, the discounted value of the expected debt converges to zero. This requires that the transversality condition

$$
\lim _{j \rightarrow \infty} E_{t}\left(\frac{1}{1+\rho}\right)^{j+1} b_{t+j}=0
$$

is fulfilled. 
Condition (6) is known as the No-Ponzi condition. It states that the public debt cannot grow forever faster than the interest rate adjusted for the inflation rate. According to this condition, no new debt must be issued by the government in order to meet the interest payments.

It states that if (6) holds, then the intertemporal budget constraint requires that the current and discounted future surpluses must be sufficient to pay-off the current public debt. It is given by

$$
b_{t}=\sum_{j=0}^{\infty} E_{t}\left(\frac{1}{1+\rho}\right)^{j+1} s_{t+j} .
$$

Starting with condition (7), in the next section we will derive the empirical testable causality relation for revenue and expenditure.

By doing this let us rewrite (7) in its first differences form:

$$
g_{t}^{r}-r_{t}=\sum_{j=0}^{\infty} E_{t}\left(\frac{1}{1+\rho}\right)^{j-1}\left(\Delta r_{t+j}-\Delta c_{t+j}\right),
$$

which assumes a stationary interest rate around a zero mean. Here, $g_{t}^{r}=g_{t}=\rho_{t} b_{t-1}$ is the total expenditure of the government including interest payments, while $c_{t}=g_{t}+\left(\rho_{t}-\rho\right) b_{t-1}$ is the same variable with the discount factor taken around a nonzero mean.

Now, the transversality condition can be written in its first differences form:

$$
\lim _{j \rightarrow \infty} E_{t}\left(\frac{1}{1+\rho}\right)^{j+1} \Delta b_{t+j}=0 .
$$

Assuming that $c_{t}, r_{t}$ and $g_{t}^{r}$ are nonstationary in the level but stationary in their first differences (e.g., they are $I(1)$-processes), then, given the relation (8), the revenue $r_{t}$ can be modeled in a linear relation with expenditure $g_{t}^{r}$. This relation between revenue and expenditure is essential to study the causality hypothesis within the cointegration model. If the linear combination between revenue and expenditure is stationary it implies that these two series are cointegrated and the government fiscal policy is consistent with the intertemporal budget constraint in the long run. 
One crucial element for testing the causality hypothesis is the (8) condition, which, because of the assumptions, implies that revenue cointegrates with expenditure. Then the relation between revenue and ependiture can be rewritten as

$$
r_{t}=\beta g_{t}^{r}+e_{t},
$$

where $\beta$ is the unknown parameter which should be estimated, while $e_{t}$ is covariance stationary term. The condition (9) stipulates that revenue and expenditure are dynamically and closely related in the long run. ${ }^{3}$

There are numerous theoretical models in the modern macroeconomic literature which imply the condition allowing for response of fiscal variables to the impulses of the GNP. Accordingly, the relation between the revenue and expenditure (9) can be rewritten in such a way that includes the GNP. Then, the trivariate model in the error-correction form can be used to analyze the causal linkages between the revenue and expenditure.

Whereas most earlier studies analyze causality by testing whether revenue is caused by expenditure in a bivariate model in Granger's terms, our causality analysis examines how useful revenue is to predict expenditure if allowing for respond of both fiscal time series to shocks coming from GNP. This study tests the causality hypothesis within an error-correction model that incorporates both the short-run causality given by the lagged terms and the long-run causality represented by the error-correction term in the VECM. The causality hypothesis can then be tested using a t-test of the coefficients on the lagged terms and the error-correction term, the latter one is here assumed to be essential to concluding that a causal relation exists between revenue and expenditure.

\section{Empirical Results}

This section briefly describes the Swiss federal historical for the 1900 to 2002 period, presents the results of the unit root and cointegration tests, and discusses the results of the causality analysis.

3 The condition (9) is essential relation to study the sustainability hypothesis. ProHL (2007) provides review of recent testing strategies of the sustainability hypothesis. She shows that the fiscal policy of Swiss federal government is consistent with the intertemporal budget constraints and is sustainable over the time period from 1862 to 2003 . Further, she evidences presence of structural breaks in cointegration relation between the revenue and expenditure, which, however, do not influence the sustainability of fiscal policy in the post-World War II sub-period. 
Figure 1. Real Revenue and Expenditure for Swiss Federal Government from 1900-1990

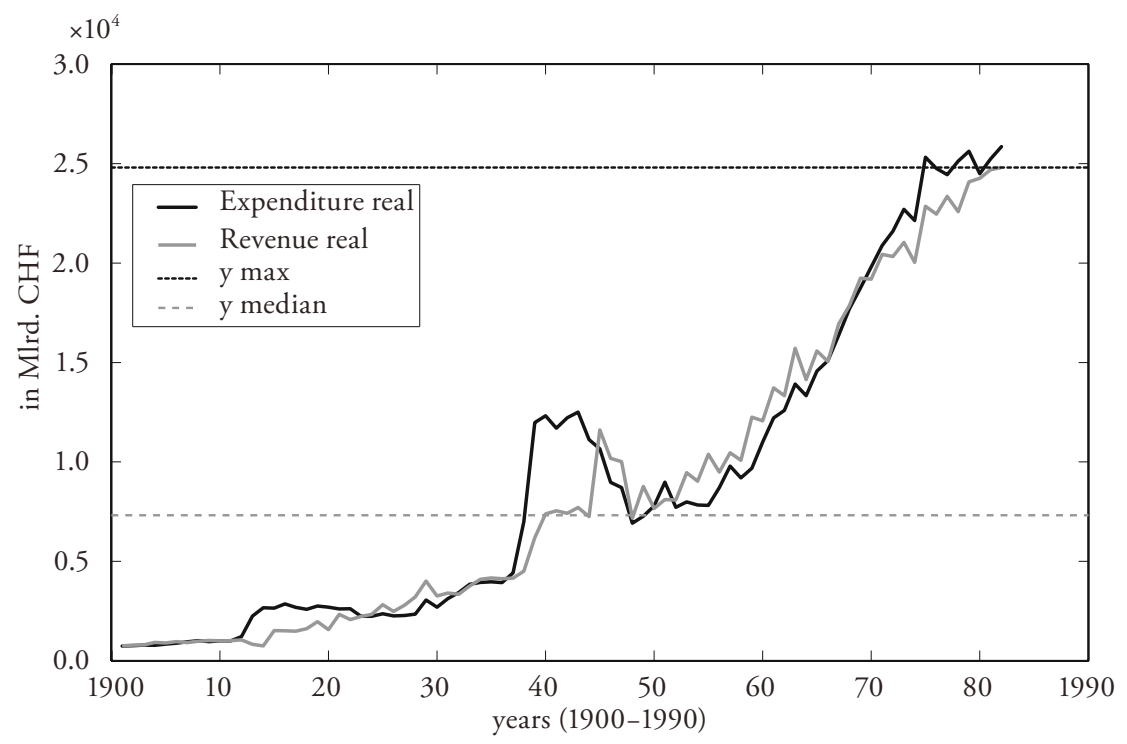

\subsection{Data}

The data used to study the causality hypothesis for the Swiss federal government is annual and covers the period 1900-2002. We use for the empirical analysis the real federal government expenditure $(E x p)$, revenue $(R e v)$, the gross national product $(G N P)$ and the GNP deflator. We consider the GNP deflator to generate real series. In order to eliminate heteroscedasticity in the data, we use the (natural) logarithms of the time series.

\subsection{Preliminary Data Analysis}

Assessment of the behavior of real revenue and expenditure begins with a graphic inspection of the time series. As Figure 1 shows, the revenue and expenditure are non-stationary over the period under study, and the series share a common stochastic trend (i.e., they move together over time). A significant gap is also observable between revenue and expenditure during World War II, which results in an excessive deficit during that time period that substantially worsened the federal government fiscal position. The figure evidences this gap results from a sudden increase in government expenditure during the World War II, supporting the 
evidence which is reported in numerous empirical studies (Prohl, 2007). This observation raises the issue whether the expenditure exhibits structural breaks which may influence its long-run equilibrium relations with the revenue. Further, we can observe that these structural changes during the World War II have may explain the reverse causality between the revenue and expenditure in the post-war sub-period. These questions will be investigated by employing formal statistical test in the next section.

\subsection{Econometric Test}

The econometric strategy performed in this paper is divided into three steps: checking the order of integration for revenue, expenditure, and GNP (all defined in real terms), testing for the cointegration of revenue, expenditure, and GNP, and finally, estimating the VECM to analyze causality.

\subsubsection{Unit Root Test}

Even though the preliminary results of the econometric tests suggest that real government revenue and expenditure are integrated, the integratedness of the variables is as yet unknown, meaning that these results should be interpreted with caution in case the variables are actually stationary. Such stationarity would be signalled by the presence of a unit root, which can be tested for as follows:

$$
r_{t}=\mu_{0}+\mu_{1} t+\rho r_{t-1}+\Delta\left(r_{t-1}\right)+w_{t},
$$

where $\mu_{0}$ is the constant, $\Delta$ denotes the difference operator, $t$ denotes the time trend, and $w_{t}$ is the error term assumed to be covariance stationary. Here, the null hypothesis of the presence of unit root is tested against the alternative hypothesis of no unit root in the time series.

First, an augmented Dickey-Fuller (ADF) test is applied to two model specifications, one that includes a constant term and a second that includes a constant and a time trend. The optimal number of lags in the unit root regression is selected using the Schwarz Information Criterion (SIC). The results are reported in Table 1.

According to the test results, revenue, expenditure, and the GNP may exhibit structural breaks during World War II, which can be verified using a unit root test that measures shifts in level. If the series has structural shifts in the level, the unit root test must accommodate them, otherwise the power of the ADF test may be distorted. 
Table 1: Unit Root Test Results

\begin{tabular}{|c|c|c|c|c|c|}
\hline \multirow[b]{2}{*}{ Series } & \multirow[b]{2}{*}{ Lags } & \multicolumn{2}{|c|}{ ADF-test (Level) } & \multicolumn{2}{|c|}{ ADF-test $(\Delta)$} \\
\hline & & $C$ & $C+T$ & C & $C+T$ \\
\hline$G N P$ & 3 & -0.693 & -1.970 & -5.008 & -5.010 \\
\hline $\operatorname{Rev}$ & 2 & -1.351 & -1.760 & -8.527 & -8.683 \\
\hline $\operatorname{Exp}$ & 1 & -1.340 & -2.751 & -5.320 & -5.381 \\
\hline
\end{tabular}

Notes: Level denotes the level of time series, $\Delta$ denotes the first differences. $C$ denotes model with intercept, $C+T$ denotes model with intercept and time trend. All lag lengths are chosen using the SIC.

Next, using the shift-in-level test proposed by Saikkonen and Luetrepohl (2002), we formally test for the presence of the shift function $f_{t}(\theta)^{\prime} \gamma$, which is simply added to the deterministic term in the ADF regression:

$$
r_{t}=\mu_{0}+\mu_{1} t+r_{t-1}+\Delta\left(r_{t-1}\right)+f_{t}(\theta)^{\prime} \gamma+w_{t},
$$

where $\theta$ and $\gamma$ are unknown parameter vectors. The presence of a shift function that may cause structural breaks in the series can then be determined as follows:

$$
f_{t}=\left\{\begin{array}{ll}
0, & t<T_{b} \\
1, & t \geq T_{b}
\end{array},\right.
$$

where $T_{b}$ denotes the time at which the structural break occurs. Taking the difference of function $f_{t}^{1}$ then allows estimation of the relation using an impulse dummy variable. The shift function can then be specified based on an exponential distribution function that allows for a nonlinear shift to a new level at time $T_{b}$ :

$$
f_{t}^{2}(\theta)=\left\{\begin{array}{ll}
0, & t<T_{b} \\
\varphi, & t \geq T_{b}
\end{array},\right.
$$

where $\varphi=1-\exp \left\{-\theta\left(t-T_{b}+1\right)\right\}$ and $f_{t}^{2}(\theta)$ is the shift term. These unit root tests probe for the presence of a level shift for all three variables real revenue, expenditure, and GNP. 
According to Saikkonen and Luetkepohl (SL) (2002), this test for a unit root should be based on an initial estimation of the deterministic term using a generalized least squares (GLS) estimator under the unit root null hypothesis, which is then subtracted from the original series. The ADF-test is then performed on the adjusted series, which includes terms to correct for estimation errors in the parameters of the deterministic portion. As in the ADF-procedure, we test the null hypothesis for a unit root against the alternative hypothesis of stationarity. Here, the asymptotic null hypothesis is nonstandard, and its critical values are those provided by Lanne, Luetkepohl and Saikkonen (2002).

The results of the unit root test for structural shifts in the level of real revenue, expenditure, and GNP performed on one model with a constant term and a second with a constant plus a time trend are given in Table 2 . The optimal lag order in the autoregressive regression is chosen using the Schwarz Information Criterion.

Table 2: Saikkonen-Luetkepohl Unit Root Test Results with Structural Breaks

\begin{tabular}{lc|ccc|ccc}
\hline & & \multicolumn{3}{|c|}{ SL-test $(C)$} & \multicolumn{3}{c}{ SL-test $(C+T)$} \\
Series & $T_{b}$ & $I D$ & $S D$ & ESD & $I D$ & $S D$ & ESD \\
\hline GNP & 1906 & -0.543 & -0.435 & -0.420 & -1.577 & -1.342 & -1.298 \\
Rev & 1915 & -1.498 & -1.690 & -1.430 & -1.961 & -2.135 & -5.416 \\
Exp & 1930 & -1.484 & -1.403 & -1.435 & -2.917 & -3.211 & -3.232 \\
\hline
\end{tabular}

Notes: $C$ denotes the model with intercept, $C+T$ denotes the model with intercept and time trend. $T_{b}$ denotes the structural break date, $I D$ denotes impulse dummy, $S D$ denotes shift dummy, ESD denotes exponential shift dummy. All lag lengths are chosen using the SIC.

The results suggest that the unit root null hypothesis cannot be rejected for real revenue, expenditure, and GNP for all specifications of the model at the 5\% level of significance. In addition, we found support for our earlier conclusion of the presence of structural shifts in the level of real revenue and expenditure. Specifically, a nonlinear gradual shift in real revenue emerged for 1915, while a shift in expenditure was observable for 1930. For interpretation of presence of structural breaks in fiscal variables the reader is refereed to Proнl (2007). She provides arguments supporting presence of shifts in revenue and expenditure over the considered time period. Therefore, given that the unit root null hypothesis for the time series cannot be rejected, we conclude that real revenue, expenditure, and GNP are apparently nonstationary (i.e., they constitute a I(1) series). 


\subsection{Cointegration Test}

Because the variables are nonstationary, we then test for cointegration in the system using more than two I(1)-series. Specifically, we estimate the number of cointegration relations that is, the number of linearly independent cointegrating vectors using two different methods.

The first, the JohANSEN (1995) maximum-likelihood procedure, is based on the following VECM:

$$
\Delta X_{t}=\Phi X_{t-1}+\Gamma_{1} \Delta X_{t-1}+\ldots+\Gamma_{p} \Delta X_{t-p}+e_{t},
$$

where $\Phi=\alpha \beta^{\prime}$ and $e_{t}$ is the error term assumed to be stationary (see JoHANSEN, 1995). The cointegration matrix $\beta^{\prime}$ is automatically normalized, which requires that the variable order be specified so that the first $r$ variables are involved in the cointegration relations. We use the Johansen LR procedure to test the null hypothesis that there are $r$ linearly independent cointegrating relations against the alternative hypothesis that there are fewer than $r$ cointegrating relations.

Next, because we observe a significant effect of structural shifts in the level on the presence of a unit root in real revenue and expenditure that may also affect long-run system relations, we perform the SAikKonen and LueTKePOHL (2000) test, which accommodates the structural shift in cointegration relationships. For this procedure, the authors propose that the VECM should be rewritten as follows:

$$
\Delta X_{t}=\Phi^{s h i f t} X_{t-1}+\Gamma_{1} \Delta X_{t-1}+\cdots+\Gamma_{p} \Delta X_{t-p}+\sum_{j=0}^{p-1} \psi_{j} \Delta d_{t-j, T_{b}}+u_{t},
$$

where $\Phi^{\text {shift }}$ is a matrix of rank $r, \psi_{j}$ is the shift variable, and $\Delta d_{t-j, T_{b}}$ is an impulse dummy variable that takes the value 1 in the period $t=T_{b}+j$ and zero otherwise.

SAikKonen and LuetKePohl (2000) also propose the following modified LR test for ranking cointegration with a level shift. First, the VECM is estimated using the Johansen (1995) procedure. These estimates are then used to estimate the parameters of the deterministic part of the model by feasible GLS (FGLS). Finally, the cointegration test is applied to the adjusted series. The critical values for the test statistic are given in Osterwald-Lenum (1992) and in Saikkonen and LuetKePohl (2000).

Accordingly, we not only employ the cointegration test for the trivariate system of revenue, expenditure, and GNP, we also test the robustness of the estimated 
results using the additional cointegration test for all possible bivariate models. The results for both JoHANSEN (1995) maximum-likelihood cointegration test and the Saikkonen and Luetrepohl (2000) test are given in Table 3. Again, the optimal number of lags in the VECM is selected using the Schwarz Information Criterion.

Table 3: Johansen and Saikkonen-Luetkepohl Cointegration Test Results

\begin{tabular}{lcc|cc|cc}
\hline \multirow{2}{*}{ Model } & & & \multicolumn{2}{|c|}{ Johansen-test } & \multicolumn{2}{c}{ SL-test } \\
& Lags & $r_{0}$ & $L R$ & $P V$ & $L R$ & $P V$ \\
\hline Model 1 & 4 & $r=0$ & $68.78^{* * *}$ & 0.000 & $52.75^{* * *}$ & 0.000 \\
& & $r=1$ & $32.85^{* *}$ & 0.010 & $15.99^{* *}$ & 0.010 \\
Model 2 & \multirow{2}{*}{4} & $r=2$ & 6.19 & 0.182 & 2.84 & 0.108 \\
& & $r=0$ & $32.42^{* * *}$ & 0.004 & $16.66^{* * *}$ & 0.007 \\
Model 3 & \multirow{2}{*}{3} & $r=0$ & $25.41^{* *}$ & 0.096 & 7.43 & 0.007 \\
& & $r=1$ & 4.10 & 0.409 & 0.41 & 0.012 \\
Model 4 & 2 & $r=0$ & $29.52^{* *}$ & 0.000 & $34.74^{* * *}$ & 0.000 \\
& & $r=1$ & 5.86 & 0.487 & 2.59 & 0.126 \\
\hline
\end{tabular}

Notes: All models include intercept term. Model 1 consists of Rev, Exp and GNP; Model 2 consists of Exp and GNP; Model 3 consists of Rev and GNP; Model 4 consists of Exp and Rev. Lags denotes the number of lags in the model. All lags are selected using the Schwarz Information Criterion. $r_{0}$ ' denotes the number of cointegrating relation under $H_{0} . L R$ denotes the $L R$-test values, and $P V$ denotes the $p$-values.

Our findings indicate that the three-dimensional system of revenue, expenditure, and GNP has two cointegrating vectors. Specifically, the Johansen LR test indicates a cointegrating rank of two, while the SaikKonen and LuetkeponL (2000) test shows that the system has two linearly independent cointegration relations.

Since any linear combination of two cointegrating vectors is also a cointegrating vector, we then study the pairwise cointegration by linearly transforming the following vectors:

i) revenue and expenditure, which represents the budgetary equilibrium,

ii) bivariate paarwise modeling of each fiscal variable with the GNP, which represents the fiscal equilibrium.

The results for the bivariate model for revenue and expenditure are given in Table 3. For this model, the Johansen cointegration test suggests the presence of 
one cointegrating vector, which implies that revenue and expenditure are cointegrated. This finding is supported by the SaikKonen and Luetkepohl (2000) test, which takes into account the structural shift in the level of the cointegrating relation. We also employ both cointegration tests to check whether (i) revenue and the GNP and (ii) expenditure and the GNP are cointegrated. The results indicate that both revenue and expenditure are cointegrated with the GNP.

In sum, the cointegration test results show that the Swiss federal governments fiscal policy is consistent with the solvency condition; that is, revenue and expenditure are cointegrated. Both revenue and expenditure are also cointegrated with the GNP. In the next step we check structural stability of cointegration relation between expenditure (revenue) and GNP because a large number of studies argues presence of structural change during World War II.

\subsection{Structural Stability of the Bivariate Cointegration Relations}

We investigate stability of cointegration relation between revenue (expenditure) and GNP by employing two-step cointegration approach of GREGORY and Hansen (1996). We estimate three models for residual-based cointegration test. The first model (A) accounts for level shift in cointegrating relation by including a dummy variable which is defined as $\hat{f}_{t}=1$ if $t>T_{b}$ and zero otherwise, where $T_{b}$ denotes a time at which structural break occurs. The second model (B), the regime shift model, additionally introduces a time trend and accounts for a change in the slope vector. Finally, the third model (C) includes a regime shift dummy variable to correct for a regime shift in the cointegrating relation. This approach can be used if the structural break $T_{b}$ is unknown. In the second step, we apply the ADF-test to examine the presence of unit root in residuals. Critical values for the cointegration test are provided by Gregory and Hansen (1996). Figure 2 and Figure 3 display the $A D F\left(T_{b}\right)$-statistic for expenditure and revenue model by using the truncated sample $[(0.15 \mathrm{t}),(0.85 \mathrm{t})]$. The lag length is selected by using the SIC.

Figure 2 shows that $\operatorname{ADF}\left(T_{b}\right)$-test values are very small for several break-points in the pre- and post-World War II sub-periods. We find the smallest test-values for the period 1925-1933, and in the mid 1950's. Thus, given these findings we conclude that cointegration relation between expenditure and GNP are highly structurally unstable over the time period under study.

Regarding cointegration model for revenue, Figure 3 provides also evidence for structural instability of cointegration relation over the period 1924-1937. Thus, graphical inspection of the estimated results shows that cointegration relation between revenue (expenditure) and GNP are not stable. This finding is 
Figure 2. Test for Structural Stability of Cointegration Relation between Expenditure and GNP of the Swiss Federal Government over 1900-1990

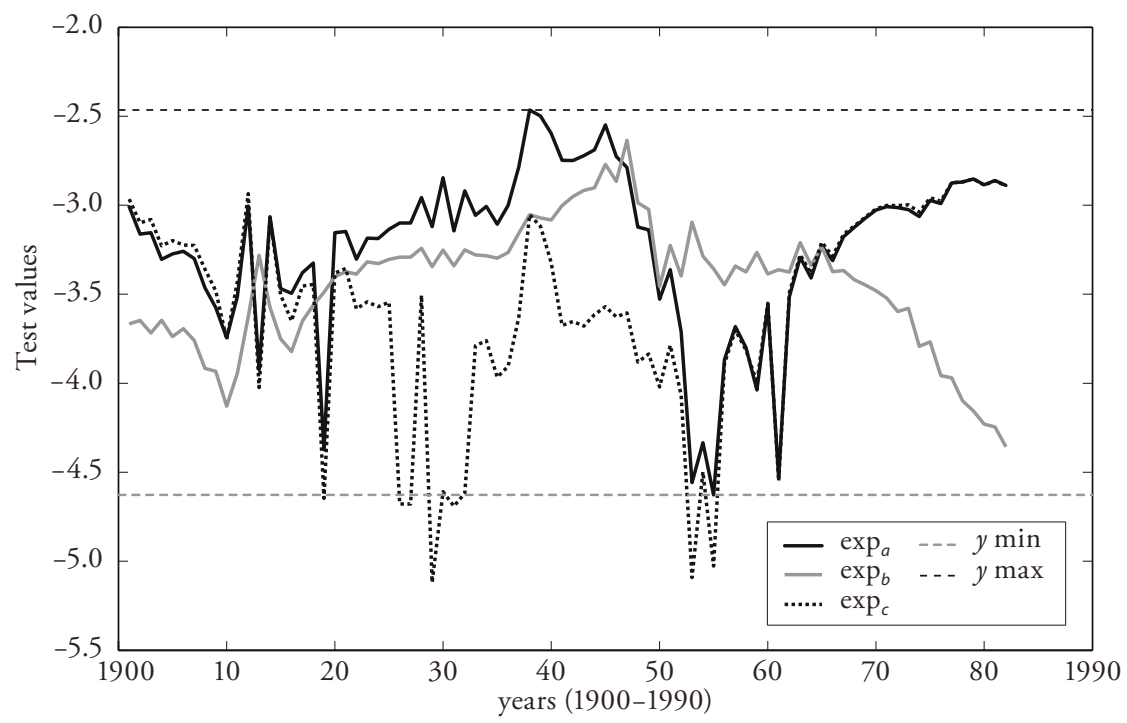

Figure 3. Test for Structural Stability of Cointegration Relation between Revenue and GNP of the Swiss Federal Government over 1900-1990

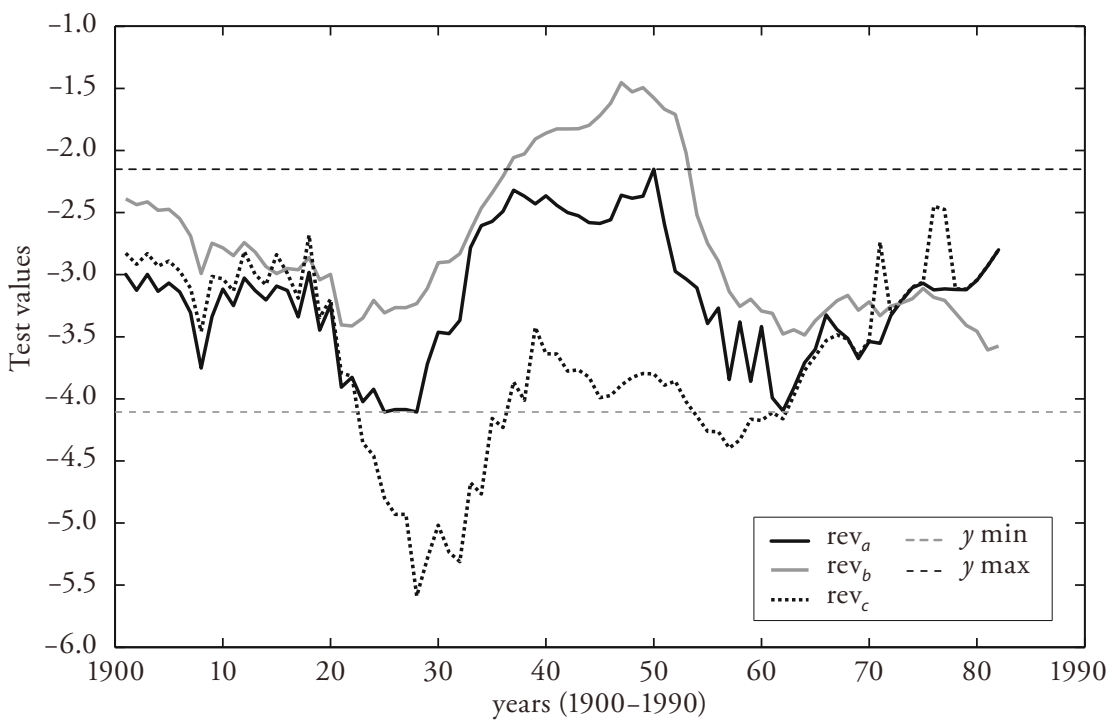


essential for our causality analysis. In the next step we estimate the VECM and employ a test of structural stability of its parameters. Next, we perform a causality analysis.

\subsection{Vector Error-Correction Model}

Given that real revenue, expenditure, and the GNP are cointegrated along two cointegrating vectors, it allows to analyze the causal linkages between them within the structural analysis of the cointegrated VAR model. Garrat, LeE, Pesaran and Shin (2000) and Pesaran and Shin (2000) provide discussion of numerous methodologies of performing structural analysis of cointegration VAR model in macroeconomic modeling. In this paper we follow the approach of GrANGER (1983) to analyse the causality between revenue and expenditure within the VECM. This methodology allows specification of the causal relationships between revenue and expenditure by considering both the short- and long-run causal relation using the error-correction term that represents the longrun causal relation.

Because we find two cointegration vectors in the trivariate system of revenue, expenditure, and GNP, we can transform these vectors into two cointegrating relations between (i) revenue and expenditure and (ii) revenue (expenditure) and the GNP. The first error-correction term that results from the cointegration model of revenue on expenditure designates the budgetary equilibrium that implies the movement of revenue and expenditure toward their long-run equilibrium (i.e., balanced) relationship. The second is the fiscal equilibrium term that suggests the equilibrium relation between the fiscal variables and the GNP.

Lastly, we estimate a VECM for revenue (expenditure) that includes not only these two error-correction terms but also budgetary and fiscal error-correction terms. We then examine long-run causality by applying a $t$-test to the model parameters estimated on the budgetary error-correction term. We estimate this model using an ordinary least-squares (OLS) estimator. The results are reported in Table 4.

As is apparent, these results provide clear evidence of bidirectional causality between revenue and expenditure using both the short- and long-run causality relation. That is, for the revenue (expenditure) model, we find a statistically significant short-run causal relation given by lagged expenditure and a long-run causal relation defined by the budgetary error-correction term. We also find that the budgetary equilibrium term in the VECM has the predicted negative sign, which implies that both revenue and expenditure adjust toward their long-run 
Table 4: The Vector Error Correction Model

\begin{tabular}{|c|c|c|}
\hline Explanatory variables & $\begin{array}{l}\text { Model for Revenue } \\
\text { Coefficient ( } t \text {-value) }\end{array}$ & $\begin{array}{c}\text { Model for Expenditure } \\
\text { Coefficient ( } t \text {-value) }\end{array}$ \\
\hline$\Delta R_{t-1}$ & - & $0.07 \quad(1.05)$ \\
\hline$\Delta R_{t-2}$ & $-0.25 \quad(5.69)$ & $0.03 \quad(0.69)$ \\
\hline$\Delta R_{t-3}$ & $0.01 \quad(0.28)$ & $0.02 \quad(0.67)$ \\
\hline$\Delta R_{t-4}$ & $-0.08 \quad(1.93)$ & $-0.05 \quad(1.07)$ \\
\hline$\Delta R_{t-5}$ & $0.14 \quad(2.92)$ & $0.14 \quad(3.53)$ \\
\hline$\Delta T G_{t-1}$ & $0.32 \quad(4.92)$ & - \\
\hline$\Delta T G_{t-2}$ & $0.06 \quad(1.47)$ & $0.14 \quad(3.95)$ \\
\hline$\Delta T G_{t-3}$ & $0.14 \quad(2.95)$ & $-0.05 \quad(1.73)$ \\
\hline$\Delta G N P_{t}$ & $0.76 \quad(6.60)$ & $0.19 \quad(1.14)$ \\
\hline$\Delta G N P_{t-1}$ & - & $-0.24 \quad(1.67)$ \\
\hline$E C T R_{t-1}$ & $-0.20 \quad(6.19)$ & - \\
\hline$E C T T G_{t-1}$ & - & $-0.11 \quad(2.55)$ \\
\hline$E C T R G N P_{t-1}$ & $-0.00 \quad(0.26)$ & - \\
\hline ECTTGGNP $P_{t-1}$ & - & $-0.01 \quad(0.95)$ \\
\hline Constant & $0.06 \quad(0.73)$ & $0.02 \quad(3.77)$ \\
\hline Dummy variables & Yes & Yes \\
\hline \multicolumn{3}{|l|}{ Diagnostic Statistics } \\
\hline S.D. Dep. var. & 0.045 & 0.047 \\
\hline$R 2$ adjusted & 0.828 & 0.803 \\
\hline S.E. of regression & 0.052 & 0.048 \\
\hline Durbin-Watson test & 1.862 & 2.183 \\
\hline LM-tests of no autocorrelation & $0.438(2)$ & $0.804(2)$ \\
\hline LM-test of no ARCH & 0.177 & 0.415 \\
\hline White Heteroskedas-ticity test & 0.759 & 2.247 \\
\hline Jarque-Bera test & 1.617 & 2.166 \\
\hline \multicolumn{3}{|l|}{ F-test: H0: $\beta_{i}=0$} \\
\hline$\beta_{\Delta T G_{t-1}}$ & 25.884 & - \\
\hline$\beta_{\Delta T G_{t-2}}$ & 2.257 & - \\
\hline$\beta_{\Delta T G_{t-3}}$ & 8.698 & - \\
\hline$\beta_{\Delta R_{t-1}}$ & - & 1.097 \\
\hline$\beta_{\Delta R_{t-2}}$ & - & 0.472 \\
\hline$\beta_{\Delta R_{t-3}}$ & - & 0.444 \\
\hline$\beta_{\Delta R_{t-4}}$ & - & 1.135 \\
\hline
\end{tabular}


Table 4 continued.

\begin{tabular}{lcc}
\hline Explanatory variables & $\begin{array}{c}\text { Model for Revenue } \\
\text { Coefficient }(t \text {-value })\end{array}$ & $\begin{array}{c}\text { Model for Expenditure } \\
\text { Coefficient }(t \text {-value })\end{array}$ \\
\hline$\beta_{\Delta R_{t-5}}$ & - & 12.438 \\
$\beta_{\Delta E C T R_{t-1}}$ & 38.287 & - \\
$\beta_{\triangle E C T G_{t-1}}$ & - & 6.477 \\
$\beta_{\triangle E C T R G N P_{t-1}}$ & 0.069 & - \\
$\beta_{\triangle E C T T G G N P_{t-1}}$ & - & 0.907 \\
\hline
\end{tabular}

Notes: $\Delta$ is the operator for first differences, $R$ denotes federal revenue, $T G$ represents federal expenditure, ECTR is the error correction term obtained from regression of the real revenue on expenditure and a constant, ECTTG is the error correction term obtained from regression of the real expenditure on revenue and a constant; ECTRGNP is the error correction term obtained from regression of the real revenue on real GNP and a constant; ECTTGGNP is the error correction term obtained from regression of the real expenditure on revenue and a constant. Robust $t$-statistics indicate heteroscedasticity consistent estimates. The F-tests indicates at what significance level the variable can be excluded from the regression. All lag lengths are chosen using the SIC.

equilibrium relation (e.g., budgetary balance). Thus, our findings emphasize budgetary equilibrium as a source of the causal relation between revenue and expenditure. At the same, the magnitude of the estimated effect and the expected negative sign also indicate that fiscal equilibrium is highly relevant for predicting revenue (expenditure).

To check the correctness of the model specifications, we apply a number of diagnostic tests. The first, the Jarque-Berra (JB) test, suggests low kurtosis (with a test statistic of 2.16) and low skewness (0.41). Because the ARCH-LM test based on the multivariate regression model can be rejected at all conventional levels of significance when we test the null hypothesis for the presence of the ARCH effect in the VECM residuals using the Lagrange multiplier (LM) test, we conclude that there is no ARCH effect in the residuals. This test provides satisfactory results, with a value of 0.80 . Finally, plotting the residuals to test for autocorrelation indicates no autocorrelation.

\subsubsection{Structural Stability}

In the next step, we perform a Chow stability test to check for the presence of structural breaks in the VECM residuals. The model is estimated from the full sample of all observations $t$, the first subsample $t_{1}$, and the last subsample $t_{2}$, where $t_{1}<T_{b}$, where $T_{b}$ is a time when the structural break occurs 
and $t_{2} \geq t-T_{b}$. The null hypothesis of the Chow-test is one of no changes in the residuals that is rejected if the test statistic, $\chi^{2}$ distributed under the null hypothesis, is sufficiently larger than the critical value.

The structural stability can potentially be assessed using three tests: the sample-split test, the breakpoint test, and the Chow forecast test. Whereas, the first assumes the constancy of the residual covariance matrix and checks against the alternative hypothesis that the other coefficients vary, the second checks for variation in the model parameters.

The results for these stability tests are presented in Table 5, which reports the estimated test values and shows the time point at which the structural break occurs.

Table 5: Structural Stability Test Results

\begin{tabular}{l|rrc|rrc}
\hline Series & \multicolumn{3}{|c|}{ Tb=1930 } & \multicolumn{3}{c}{ Tb=1945 } \\
\hline Test statistic & 124.221 & 95.647 & 0.494 & 164.540 & 55.784 & 0.325 \\
$P$-valueboot & 0.000 & 0.000 & 0.980 & 0.000 & 0.000 & 0.990 \\
\hline
\end{tabular}

Notes: $T_{b}$ denotes the structural break data, $B P$ denotes break point Chow-test, $S S_{V E C M}$ denotes

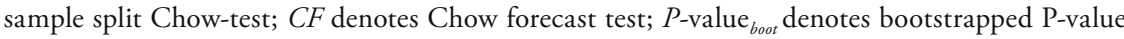
for Chow test. All lag lengths are chosen using the SIC.

As the results given in the table imply, the relation between real revenue, expenditure, and the GNP is characterized by high structural instability. These structural shifts are also visible in Figure 1, which shows that World War II significantly affected the fiscal stance of the Swiss federal budget.

\subsubsection{Causality Test}

We test the causality hypothesis using both the Granger non-causality test and the test for instantaneous causality. The revenue $\left(r_{t}\right)$ is said to Granger-cause expenditure $\left(g_{t}^{r}\right)$ if it provides useful information for predicting expenditure. We test this hypothesis for this model using a level VAR without exogenous variables.

The null hypothesis that revenue $\left(r_{t}\right)$ does not Granger-cause expenditure $\left(g_{t}^{r}\right)$ is represented by the following equation and tested using the Wald test:

$$
H_{0}: w_{21, n}=0, n=1,2, \cdots, p+1 \text {. }
$$


We then test for instantaneous causality, which implies a nonzero correlation between $r_{t}$ and $g_{t}^{r}$. To test this hypothesis, we examine whether the following null hypothesis is rejected against the alternative hypothesis of nonzero covariance between the two error vectors:

$$
H_{0}: \quad E\left(u_{1 t} u^{\prime}{ }_{2 t}\right)=0
$$

The Wald test for this hypothesis is described in Luetrepohl, Teraesvirta and Wolters (1999).

To show that the results depend on the Granger causality hypothesis being tested in a trivariate system containing real GNP, we also estimate a bivariate VECM and examine the causality hypothesis for real revenue and expenditure. The results of the causality tests are given in Table 6 .

Table 6: Causality Test Results

\begin{tabular}{llrccc}
\hline & & \multicolumn{2}{c}{ GC } & \multicolumn{2}{c}{ IC } \\
Model & & Test & $P$-value & Test & $P$-value \\
\hline Model 1 & Rev $\rightarrow$ Exp & 2.925 & 0.003 & 8.061 & 0.017 \\
& Exp $\rightarrow$ Rev & 7.447 & 0.000 & 5.245 & 0.072 \\
Model 2 & Rev $\rightarrow$ Exp & 4.262 & 0.002 & 1.240 & 0.265 \\
& Exp $\rightarrow$ Rev & 10.259 & 0.000 & 1.240 & 0.265 \\
\hline
\end{tabular}

Notes: GC denotes Granger causality test; $I C$ denotes instantaneous causality test; Model 1 consists of Rev, Exp and GNP; Model 2 consists of Rev and Exp. Test denotes the statistic value, $P$-value denotes $p$-values.

As the table shows, when we estimate the model that includes real GNP, the null hypothesis of no Granger causality can be rejected at all conventional levels of significance for bidirectional causality of $r_{t}$ and $g_{t}^{r}$. This finding provides clear and robust evidence of a bidirectional feedback relation between revenue and expenditure for the period under study.

These results for the bivariate VEC model are also consistent with findings reported in earlier studies. For example, just as we cannot reject the null hypothesis of no causal relation at any conventional level of significance, earlier studies find no evidence of bidirectional causality resulting from omitted information in the relations between revenue or expenditure and the GNP. 


\section{Determinants of the Budget Deficit}

In this section we focus on the main determinants of the federal budget deficit. This question translates into testing whether the federal budget deficit can be explained by macroeconomic factors such as expected inflation, the cyclical position of the economy which influences tax revenues and temporary changes in the structure of federal expenditures. Following the theoretical approach of the tax smoothing model of BARRO (1979), we analyze whether the above-mentioned factors which explain the federal budget deficit in Switzerland in the post-war period differ significantly from those during the World Wars. The tax smoothing approach models the budget deficit as a linear function of the variations of the expected rate of inflation, the temporary fluctuations of the government expenditures during wartime, cyclical fluctuations of the output during the economic booms and the recessions. We extend this model to the following system of equations

$$
\begin{gathered}
d_{t}=\alpha+\beta_{1} \pi_{t}^{e}+\beta_{2} g_{t}^{r}+\beta_{3} R G D P_{t}+\beta_{4} R M G_{t}+\beta_{5} d_{t-1}+\beta_{t}, \\
\pi_{t}^{e}=\gamma_{0}+\gamma_{1} \pi_{t-1}+\gamma_{2} \pi_{t-2}+\gamma_{3} m 3_{r, t-1}+\gamma_{4} G D P r_{t-1}+\gamma_{5} G D P r_{t-1}+e_{t} .
\end{gathered}
$$

In this model $d_{t}$ is the nominal federal budget deficit divided by the nominal GDP, $\pi_{t}^{e}$ represents expected inflation is the nominal federal debt divided by the nominal GDP, $R G D P_{t}$ is a measure of temporary output fluctuations, i.e. the output gap, $R M G_{t}$ a measure of the temporary fluctuations of federal military expenditures, of its deviation from its long-run equilibrium path, $\pi_{t}$ is the annual inflation rate calculated on the basis of the consumer price index, $m 3_{r, t}$ is the growth rate of real money M3, and GDPr the growth rate of real GDP.

Theory predicts that cyclical fluctuations in output which are caused by an economic boom and/or a recession have a significant impact on the budget deficit: the deficit increases when the output gap is negative, i.e., when it lies below its 'normal' level. We examine the hypothesis by testing the effect of the output gap which is defined as a difference between the real GDP and the trend of the real GDP. The coefficient of the output gap variable in model (18) is suggested to be close to one. A significant determinant of the budget deficit is a temporary in-crease in public expenditures during wartime. As shown by BARro (1979), such fluctuations are caused by an increase in federal military expenditures during wartime. Accordingly, we test this hypothesis by examining the effect of temporary fluctuations in military expenditures on the budget deficit. The theory predicts that the estimated coefficient may be close to one if an increase in 
expenditures above the 'normal' level does not cause either a significant change in civil expenditures or an unusual tax increase. The intertemporal budget constraint links the budget deficit and the public debt. The budget deficit is defined as sustainable if it responds negatively to an increase in public debt. In order to improve the intertemporal budget balance, the government should compensate an increase in public debt by reducing the non-interest expenditures and/or by increasing taxes. BARRO (1979) assumes that the budget deficit is also a linear function of the expected inflation rate. To test this hypothesis, we calculate the expected inflation by out-of-sample forecasts with rolling estimation of the equation (19). The predicted coefficient on the expected inflation rate in the budget deficit equation is suggested to be close to one. Using OLS, the results for the deficit equation over the entire sample from 1930 to 2002 are as follows:

$$
\begin{aligned}
d_{t}= & 0.006+0.113+0.028 \\
& -0.014 R G D P_{t}+0.038^{* * *} R M G_{t}+0.589^{* * *} d_{t-1}+e_{t},
\end{aligned}
$$

where $S E R=0.009, R^{2}=0.852, D .-W .=1.496$ and $J .-B .=0.527$.

The results for the sub-period from 1946 to 2002 are given by (2.11)

$$
\begin{aligned}
d_{t}= & -0.001+0.661^{* * *} \pi_{t-1}+0.020^{*} \pi_{t-2} \\
& -0.051^{*} R G D P_{t}+0.015^{*} R M G_{t}+0.335^{* *} d_{t-1}+e_{t},
\end{aligned}
$$

where $S E R=0.007, R^{2}=0.380, D .-W .=1.653, J .-B .=0.197$, and *, **, *** denote significance at the 1,5 and $10 \%$ significance levels.

The output gap has the expected negative impact on the public deficit, but its impact is neither for the entire sample nor for the period after World War II significant. Contrary to this, military expenditure does have a significant impact, at the 1 percent level for the entire period and still at the 10 percent level for the second sub-period. However, its estimated coefficient is far away from the theoretically expected value of one, indicating that civilian expenditure has been reduced and/or taxes increased to finance part of the additional military expenditure during the wars. Finally, the expected inflation rate is insignificant for the whole period, but significant for the second one, with a coefficient which is considerably below but statistically not different from one. 


\section{Concluding Remarks}

One essential question considered in this study is whether the government should react to an increase in budget deficit by simultaneously increasing tax rates and cutting expenditures. However, despite wide theoretical support of statement that such policy instruments can eliminate the budget deficit, the empirical evidence provides no clear support for such a favorable outcome. To test this hypothesis, the causal analysis of Swiss federal government data for the 1900-2002 time period employs a more advanced econometric strategy that allows revenue and expenditure to respond to the GNP and derives a trivariate condition for the causality hypothesis. Additionally, recognizing that revenue, expenditure, and GNP are cointegrated, it examines the dynamic within a vector error-correction model that allows revenue, expenditure, and the GNP to respond to the policy regime changes that cause structural breaks in their long-run relationship and accommodates structural breaks in the level of the cointegration relation.

Our results indicate that revenue, expenditure, and the GNP are cointegrated, but the long-run relationship between them is structurally unstable. In addition, according to a cointegration test that accommodates structural shifts in level, the trivariate system of revenue, expenditure, and GNP has two cointegrating vectors and bivariate pairwise cointegration exists between revenue and expenditure, revenue and the GNP, and expenditure and the GNP.

Finally, a VECM containing budgetary and fiscal equilibrium-related terms estimated because all three series are cointegrated provides clear evidence of bidirectional causality between revenue and expenditure once the GNP is incorporated into the model. Likewise, the fact that the test for instantaneous causality does not allow rejection of the null hypothesis of no causal relation between revenue and expenditure in a bivariate model supports our contention that a multivariate model which allows revenue and expenditure to respond to the GNP is a more appropriate method for causality analysis.

\section{References}

Alho, Juha, and Reijo Vanne (2006), "On Predictive Distributions of Public Net Liabilities", International Journal of Forecasting, Vol. 22, pp. 725-733. Ahiakpor, James, and Saleh Amirkhalkhali (1989), "On the Difficulty of Eliminating Deficits with Higher Taxes: Some Canadian Evidence”, Southern Economic Journal 56, pp. 24-31. 
Alesina, Alberto, and Roberto Perotti (1995), "Fiscal Expansion and Fiscal Adjustment in OECD Countries", NBER Working Paper No. 5214, Cambridge, MA.

Anderson, William, Myles Wallace, and John Warner (1986), "Government Spending and Taxation: What Causes What?", Southern Economic Journal 56, pp. 24-31.

Baghestani, Hamid, and Robert McNown (1994), "Do Revenue or Expenditure Respond to Budgetary Disequilibria?”, Southern Economic Journal 60, pp.311-322.

Barro, Robert (1979), "On the Determination of the Public Debt", Journal of Political Economy 81, pp.940-971.

Bohn, Henning (1991), "Budget Balance through Revenue or Spending Adjustments? : Some Historical Evidence for the United States", Journal of Monetary Economics, 27(3), pp. 333-359.

Buchanan, James, and Richard Wagner (1977), "Democracy in Deficit: The Political Legacy of Lord Keynes", Academic Press New York.

Friedman, Milton (1978), "The Limitations of Tax Limitation", Policy Review XX, pp. 7-14.

Garrat, Anthony, Kevin Lee, Hashem Pesaran and Shin, Yongcheol (2000), "A Structural Cointegrating VAR Approach to Macroeconometric Modelling", in S. Holly and M. Weale (eds), Econometric Modelling: Techniques and pplications, Cambridge University Press, Cambridge, pp. 94-131.

Granger, Clive (1983), "Cointegrated Variables and Error Correction Models", UCSD Discussion Paper No. 83-13a.

Gregory, Allan and Bruce Hansen (1996), "Residual Based Test for CoIntegration in Models with Regime Shifts", Journal of Econometrics 70, pp. 99-126.

Hasan, Seid, and Abdul Sukar (1995), "Short and Long-Run Dynamics of Expenditure and Revenue and the Government Budget Constraint: Further Evidence", Journal of Economics 22, pp. 35-42.

Hoover, Kevin, and Steven Sheffrin (1992), "Causation, Spending, and Taxes: Sand in the Sandbox or Tax Collector for the Welfare State?", American Economic Review 82, pp. 225-248.

Johansen, Soren (1995), "Identifying Restrictions of Linear Equations with Applications to Simultaneous Equations and Cointegration", Journal of Econometrics 69, pp. 111-132.

Lanne, Marku, Helmut Luetkepohl, and Pentij Saikkonen (2002), "Comparison of Unit Root Tests for Time series with Level Shifts", Journal of Time Series Analysis 23, pp. 667-685. 
Luetkepohl, Helmut, Timo Teraesvirta, and Juergen Wolters (1999), "Investigating Stability and Linearity of a German M1 Money Demand Function", Journal of Applied Econometrics 14, pp. 511-525.

Manage, Neela, and Michael Marlow (1986), "The Causal Relation between Federal expenditure and Receipts", Southern Economic Journal 52, pp. 617-629.

Miller, Stephen, and Frederik Russek (1989), "Co-Integration and ErrorCorrection Models: The Temporal Causality between Government Taxes and Spending", Southern Economic Journal 57, pp. 221-229.

Osterwald-Lenum, Michael (1992), "A Note with Fractiles of the Asymptotic Distribution of the Maximum Likelihood Cointegration Rank Test Statistics: Four Cases", Oxford Bulletin of Economics and Statistics 54, pp. 461-472.

Payne, James (2003), "A Survey of International Empirical Evidence on the TaxSpend Debate", Public Finance Review 31, pp. 302-324.

Pesaran, Hashem and Shin, Yongcheol (2000), "Structural Analysis of vector Error Correction Models with Exogenous I(0) Variables", Journal of Econometrics, 97, pp. 293-343.

Prohl, Silika (2007), Cointegration Test of Sustainability of Public Debt. PhD Thesis, University of StGallen.

Ram, RaI (1988), "A Multicountry Perspective on Causality between Government Revenue and Government Expenditure", Public Finance 43, pp. 261-269.

Saikkonen, Pentti and Helmut Luetkepohl (2000), "Testing for the Cointegrating Rank of a VAR Process with Structural Shifts", Journal of Business Economic Statistics 18, pp. 451-464.

\section{SUMMARY}

This paper examines the causality between the Swiss federal governments revenue and expenditure over the 1900 to 2002 period by estimating the short- and longrun relation within an error-correction approach that places more emphasis on the long-run relation as a source of the causal link. The results suggest both that the fiscal policy is consistent with the governmental budget constraint - revenue and expenditure are cointegrated, and revenue cause expenditure and vice versa. There is also evidence that World War II had a significant impact on the stability of the cointegrating relation between revenue and expenditure. 